\title{
PENELITIAN PENAMBAHAN BAHAN SERBUK DOLOMITE DAN PASIR BRANTAS PADA CAMPURAN ASPAL BETON
}

\author{
Faisal abdul yusuf ${ }^{* 1}$, Ahmad Ridwan ${ }^{2}$, Yosef Cahyo S P ${ }^{3}$. \\ ${ }^{1,2,3}$ Fakultas Teknik, Universitas Kadiri. \\ e-mail:*1Faizalhsfci007@gmail.com, 22ahmad_ridwan@unik-kediri.ac.id, \\ 3 Yosef.cs@unik-kediri.ac.id.
}

\begin{abstract}
Asphalt Concrete (Hotmix) is a mixture of coarse aggregate, fine aggregate, and filler (filler) with asphalt binder in high-temperature conditions (heat) with a composition that is examined and regulated by technical specifications. In this research, concrete asphalt mixture was added with dolomite powder as a mixture in filler to be an alternative material for portland cement filler mixture to minimize the price of portal and cement, which is increasingly expensive, and brantas sand as fine aggregate to study and determine the effect of dolomite powder and brantas sand in the mixture asphalt concrete with the addition of levels of 5\%,10\%, and 15\%. From the results of the study obtained the value of adding dolomite powder with levels of 5\%, 10\%, 15\% at VIM values of $11.99 \%, 15.28 \%, 10.29$, VMA value of $26.30 \%, 29.05 \%, 24.88 \%$, VFB value of $54.49 \%, 48.33 \%$, $58.81 \%$, stability value of $3402.503 \mathrm{~kg}, 3294.030 \mathrm{~kg}, 1958.946 \mathrm{~kg}, M Q$ value $733,8130 \mathrm{~kg}$, $456,1891 \mathrm{~kg}, 471,9089 \mathrm{~kg}$ and from the testing chart the optimum content is at levels $5.5 \%$ to $8 \%$ and the maximum level is at $5 \%$ level.
\end{abstract}

Keywords: $\quad$ Dolomite Powder, Brantas Sand, Concrete Asphalt, Powder Effect dolomite.

\begin{abstract}
Abstrak
Aspal Beton (Hotmix) adalah campuran agregat kasar, agregat halus, dan bahan pengisi (Filler) dengan bahan pengikat aspal dalam kondisi suhu tinggi (panas) dengan komposisi yang diteliti dan diatur oleh spesifikasi teknis. Pada penelitian ini, campuran aspal beton diberi bahan tambahan serbuk dolomite sebagai campuran pada filler agar menjadi bahan alternativ campuran filler semen portaland untuk meminimalisir harga semen portaland yang semakin mahal dan pasir brantas sebagai agregat halus untuk mempelajari dan mengetahui pengaruh serbuk dolomit dan pasir brantas pada campuran aspal beton dengan penambahan kadar 5\%,10\%, dan 15\%.dari hasil penelitian didapat nilai penambahan serbuk dolomite dengan kadar $5 \%, 10 \%, 15 \%$ pada nilai VIM sebesar 11,99\%, 15,28\%, 10,29 , nilai VMA $26,30 \%, 29,05 \%, 24,88 \%$, nilai VFB $54,49 \%, 48,33 \%, 58,81 \%$, nilai stabilitas $3402,503 \mathrm{~kg}, 3294,030 \mathrm{~kg}, 1958,946 \mathrm{~kg}$, nilai MQ 733,8130 kg, 456,1891 kg, 471,9089 kg dan dari grafik pengujian kadar optimum pada kadar 5,5\% sampai $8 \%$ dan kadar maximum pada kadar $5 \%$.
\end{abstract}

Kata Kunci : Serbuk Dolomit, Pasir Brantas, Aspal Beton, Pengaruh Serbuk dolomite. 


\section{PENDAHULUAN}

Perkerasan jalan yang digunakan dalam pembuatan jalan [1][2][3]. Aspal beton sering kali digunakanan dikarenakan mempunyai kelebihan yaitu kemampuannya dalam mendukung beban berat lalu-lintas atau kendaraan yang tinggi dan mempunyai ketahanan yang baik terhadap cuaca [4][5][6], dalam segi harga aspal beton lebih murah dibandingkan dengan beton. Aspal beton terdiri dari campuran agregat bergradasi menerus dengan bahan bitumen. Pengunaan serbuk dolomite sebagai campuran pada filler adalah sebagai bahan alternative dan penekan biaya dikarenakan harga yang lebih murah dibandingkan dengan harga semen yang semakin mahal dan pengunaan pasir brantas pada agregat halus untuk mengenalkan bahan lokal yang mudah di jumpai kususnya daerah nganjuk dan kediri. penelitian pengaruh penambhan filler abu ampas tebu pada campuran aspal terhadap sifat marshall. Pada penelitiannya membuat 18 sampel atau benda uji dengan kadar ampas tebu 2\%, variasi aspal 5,5\%,6\%, 6,5\%,7\%, 7,5\%, 8\%. Dari penelitianya menghasilkan kadar aspal optimum didapat pada 6,5\% dengan nilai stabilitas 1013 kg,densty 2,298 gr/cc, VMA 17,77\%, VIM 4,49\%, flow 3,70 mm dan MQ 274 kg/mm.

penelitian studi karakteristik campuran aspal beton lapis aus (AC-WC) menggunkan aspal penetrasi 60/70 dengan penambahan lateks. Tujuan penelitianya untuk mengetahui karakteristik campuran AC-WC pada kadar aspal optimum penambahan dengan variasi lateks 0\%, 2\%, 4\%, $6 \%, 8 \%$ dan $10 \%$ terhadap total perekat. Pada penelitiannya dipilih variasi latek $4 \%$ terhadap total perekat, karena dari hasl pengujan aspal memenuhi spesifikasi [7][8][9].

\section{METODE PENELITIAN}

\subsection{Lokasi Penelitian.}

Penelitian ini dilakukan di Laboratorium Teknik Sipil Universitas Kadiri, pada awal bulan maret dan selesai pada bulan juni dengan menggunakan metode Eksperimen.

\subsection{Data umum.}

Tahapan-tahapan pada penelitian ini meliputi persiapan pelaksanaan, alat dan bahan serta analisa data. Tahapan pertama dimulai dengan persiapan waktu dan pelaksanaan, tahap kedua persiapan alat yang sudah tersedia di laboratorium, tahap ketiga pengumpulan bahan material yang di dapat dari kantor Dinas PUPr Kabupaten Nganjuk, tahap ke empat melakukan pengujian bahan material, tahap kelima pembuatann sempel benda uji berbentuk silinder sebanyak 9 buah dengan penambahan kadar serbuk dolomite 5\%, 10\%, 15\% dan tahap terakhir pengujian benda uji.

\subsection{Perkerasan jalan.}

Perkerasan jalan adalah bagian jalan yang diperkeras dengan lapis konstruksi tertentu, 
yang memiliki ketebalan, kekuatan, dan kekakuan, serta kestabilan tertentu agar mampu menyalurkan beban lalu lintas diatasnya ke tanah dasar secara aman. Perkerasan jalan terdiri 3 lapisan yaitu, lapis pondasi atas, lapis pondasi bawah, lapisan tanah dasar [10][11][12]. Perkerasan jalan terdiri atas tiga jenis perkerasan yaitu:

1. Perkerasan Lentur

2. Perkerasan Kaku

3. Perkerasan komposit

Pada jalan-jalan yang ada indonesia perkerasan jalan yang paling sering digunakan atau yang lebih banyak pengunaanya yaitu perkerasan lentur dibandingkan perkerasan kaku karena perkerasan lentur memiliki karakteristik yang baik dan cocok digunakan pada jalan-jalan di indonesia [13] [14][15].

\subsection{Lapis Aspal Beton (LASTON)}

Lapisan aspal beton adalah suatu lapisan pada konstruksi jalan yang terdiri dari campuran aspal keras dan agregat, dicampur dan dihampar dalam keadaan panas serta dipadatkan pada suhu tertentu [16].Lapis aspal beton terdiri dari campuran agregat halus, agregat kasar, dan bahan pengisi (filler) dicampur dengan penetration grade aspal [17]. dari pencampuran agregat dan bahan pengisi (filler), dan aspal menghasilkan sifat mengunci (interlocking) [18].

\subsection{Perkerasan jalan.}

Bahan penyusun campuran Laston (AC) terdiri dari :

\subsubsection{Aspal}

Aspal adalah komponen utama dalam pembuatan laston, Aspal terbuat dari suatu unsur dari minyak bumi yang paling kasar tetapi bukan hasil proses utama dalam distilasi minyak bumi. Material ini berwarna hitam kecoklatan bersifat visikoelastis sehingga melunak dan mencair apa bila dipanaskan pada suhu tertentu dan mengeras pada suhu rendah.

\subsubsection{Agregat}

Agregat adalah butiran-butiran partikel mineral yang salah satu pengunaanya dalam kontruksi kegunaan agregat dalam bidang konstruksi antara lain sebagai bahan campuran dengan semen untuk pembuatan beton, bahan untuk perkerasan jalan, material pengisi dll. Berdasarkan didapatkanya agregat terdiri dari agregat alam dan agregat buatan.

Dalam pengunaan agregat pada campuran beraspal secara umum terbagi dalam 2 jenis [19], yaitu:

\section{Agregate halus}

Agregat halus adalah material dengan butiran-butiran kecil yang berspesifikasi lolos pada saringan Nomor 8 dan tertahan pada saringan Nomor 200. 


\section{Agregat kasar}

Agregat Kasar adalah material dengan sepesifikasi tertahan pada saringan Nomor 8 .

\subsubsection{Pasir brantas (Sebagai Agregat halus)}

Pasir adalah material yang terbentuk dari silikon dioksida yang berbentuk butiran yang memiliki ronga-ronga cukup besar. Butiran pasir umumnya berukuran kisaran antara 0,0625 mm sampai $2 \mathrm{~mm}$.

\subsubsection{Bahan Pengisi(filler)}

Bahan pengisi (filler) merupakan salah satu bahan pada campuran aspal beton bahan ini harus lolos pada saringan No.200 (0,075 mm).

\subsubsection{Serbuk Dolomite (Sebagai bahan campuran filler)}

Dolomit adalah suatu mineral karbonat anhidrat yang terbentuk dari kalsium magnesium karbonat $\mathrm{CaMg}(\mathrm{CO} 3) 2$.

\subsubsection{Bahan Bitumen}

Bitumen merupkan zat perekat berwarna hitam atau gelap, yang di peroleh dari alam ataupun hasil produksi. Material pembentuk bitumen adalah senyawa hidrokarbon seprti aspal tar atau pitch.

\subsection{Metode Perencanaan Campuran.}

Rancangan campuran bertujuan untuk mendapatkan campuran aspal beton dari bahan material sehingga menghasilkan campuran yang memenuhi spesifikasi yang ditetapkan. Di indonesia metode rancangan campuran yang paling banyak digunakan adalah metode rancangan campuran berdasarkan pengujian pengujian empiris, dengan mengunakan alat marshall.

\subsection{Metode Marshall}

Rancangan campuran berdasarkan metode Marshall ditemukan oleh Bruce Marshall, dan telahh distandarisasi oleh ASTM ataupun ASSHTO melalui beberapa modifikasi, yaitu ASTM d 1559-76 atau AASHTO T-245-90. Prinsip dasar metode marshall adalah pemeriksaan

stabilitas dan kelelehan (flow), serta analisis kepadatan dan pori dari campuran padat yang terbentuk [20][21]. Beberapa hal yang harus di persiapkan dalam pengujian Marshall antara lain :

1. Jumlah sampel atau benda uji yang dipersiapkan.

2. Persiapan alat dan bahan yang akan digunakan.

3. Persiapan menentukan temperatur suhu pada saat pencampuran dan pemadatan. 
4. Persiapan campuran aspal beton.

5. Pemadatan sampel atau benda uji.

6. Persiapan untuk pengujian Marshall.

\subsection{Alat dan bahan.}

Alat yang di pergunkaan pada saat penelitian berlangsung :

1. Satu set saringan

2. Alat pengujian pemeriksaan aspal

3. Alat uji pemeriksaan agregat, Los Angeles

4. Alat tekan marshall

5. Alat cetak benda uji berbentuk silinder atau tabung

6. Marshall Automatic Compactor

7. Ejector

8. Water Bath

Dalam penelitian ini bahan-bahan yang diperlukan adalah :

a. Serbuk Dolomite yang didapat dari Lab kantor Dinas PUPr Kabupaten

Nganjuk.

b. Pasir Brantas yang didapat dari kantor kantor Dinas PUPr Kabupaten Nganjuk.

c. Agregat kasar dan medium didapat dari kantor Dinas PUPr Kabupaten Nganjuk.

d. Aspal yang didapat dari kantor Dinas PUPr Kabupaten Nganjuk

\subsection{Persiapan JMF ( Job Mix Formula )}

Dalam penelitian ini mengunakan Job Mix Formula sebagai berikut :

Tabel 1. Proporsi campuran serbuk dolomite sebesar 5\%.

\begin{tabular}{|c|l|l|l|l|}
\hline No & \multicolumn{1}{|c|}{ Bahan } & \multicolumn{1}{c|}{ Jumlah\% } & \multicolumn{1}{c|}{ Individual } & \multicolumn{1}{c|}{ Comulative } \\
\hline 1 & Agregat kasar & 23,42 & 281 gram & 281 gralm \\
\hline 2 & Agregat medium & 30,92 & 371 gram & 652 gram \\
\hline 3 & Agregat halus( pasir brantas) & 37,50 & 450 gram & 1102 gram \\
\hline 4 & Filler & 1,74 & 20,9 gram & 1122,9 gram \\
\hline 5 & Dolomite & 0,09 & 1,1 gram & 1124 gram \\
\hline 6 & Aspal & 6,33 & 76 gram & 1200 gram \\
\hline
\end{tabular}

Sumber : Lab. Teknik Sipil Universitas Kadiri

Tabel 2. Proporsi campuran serbuk dolomite sebesar $10 \%$.

\begin{tabular}{|c|l|l|l|l|}
\hline No & \multicolumn{1}{|c|}{ Bahan } & \multicolumn{1}{c|}{ Jumlah\% } & \multicolumn{1}{c|}{ Individual } & \multicolumn{1}{c|}{ Comulative } \\
\hline 1 & Agregat kasar & 23,42 & 281 gram & 281 gralm \\
\hline 2 & Agregat medium & 30,92 & 371 gram & 652 gram \\
\hline 3 & Agregat halus( pasir brantas) & 37,50 & 450 gram & 1102 gram \\
\hline 4 & Filler & 1,65 & 19,8 gram & 1121,8 gram \\
\hline 5 & Dolomite & 0,18 & 2,2 gram & 1124 gram \\
\hline 6 & Aspal & 6,33 & 76 gram & 1200 gram \\
\hline
\end{tabular}

Sumber : Lab. Teknik Sipil Universitas Kadiri. 
Tabel 3. Proporsi campuran serbuk dolomite sebesar $15 \%$.

\begin{tabular}{|c|l|l|l|l|}
\hline No & \multicolumn{1}{|c|}{ Bahan } & \multicolumn{1}{c|}{ Jumlah\% } & \multicolumn{1}{c|}{ Individual } & \multicolumn{1}{c|}{ Comulative } \\
\hline 1 & Agregat kasar & 23,42 & 281 gram & 281 gralm \\
\hline 2 & Agregat medium & 30,92 & 371 gram & 652 gram \\
\hline 3 & Agregat halus( pasir brantas) & 37,50 & 450 gram & 1102 gram \\
\hline 4 & Filler & 1,56 & 18,7 gram & 1122,7 gram \\
\hline 5 & Dolomite & 0,27 & 3,3 gram & 1124 gram \\
\hline 6 & Aspal & 6,33 & 76 gram & 1200 gram \\
\hline
\end{tabular}

Sumber : Lab. Teknik Sipil Universitas Kadiri.

\section{HASIL DAN PEMBAHASAN}

Dari hasil peneitian dan pengetesan mengunakan alat marshall maka didapatkan lah hasil sebagai berikut :

Tabel 4. Hasil pengujian karakteristik Marshall untuk seluruh parameter

\begin{tabular}{|c|c|c|c|c|c|c|c|}
\hline No & $\begin{array}{c}\text { Kadar } \\
\text { Dolomite }\end{array}$ & $\begin{array}{c}\text { VM } \\
\text { A }\end{array}$ & $\begin{array}{c}\text { VIM } \\
\%\end{array}$ & $\begin{array}{c}\text { VF } \\
\text { B }\end{array}$ & $\begin{array}{c}\text { Stabilitas } \\
\text { Kg }\end{array}$ & $\begin{array}{c}\text { Flow } \\
\text { Mm }\end{array}$ & $\begin{array}{c}\text { MQ } \\
\mathrm{kg} / \mathrm{mm}\end{array}$ \\
\hline 1 & $5 \%$ & 26,30208134 & 11,99138 & 54,49394 & 3402,503 & 4,25 & 733,813 \\
\hline 2 & $10 \%$ & 29,05717184 & 15,28146 & 48,33611 & 3294,03 & 4,46 & 456,1891 \\
\hline 3 & $15 \%$ & 24,8843905 & 10,29842 & 58,81597 & 1958,946 & 4,15 & 471,9089 \\
\hline & Spesifikasi & $15 \%<$ & $3-5 \%$ & $65 \%<$ & $800 \mathrm{~kg}<$ & $\begin{array}{c}2-4 \\
\mathrm{~mm}\end{array}$ & $\operatorname{min~} 350$ \\
\hline
\end{tabular}

Sumber : Lab. Teknik Sipil Universitas Kadiri.

Grafik 1. Hubungan antara kadar serbuk dolomite dengan nilai VIM

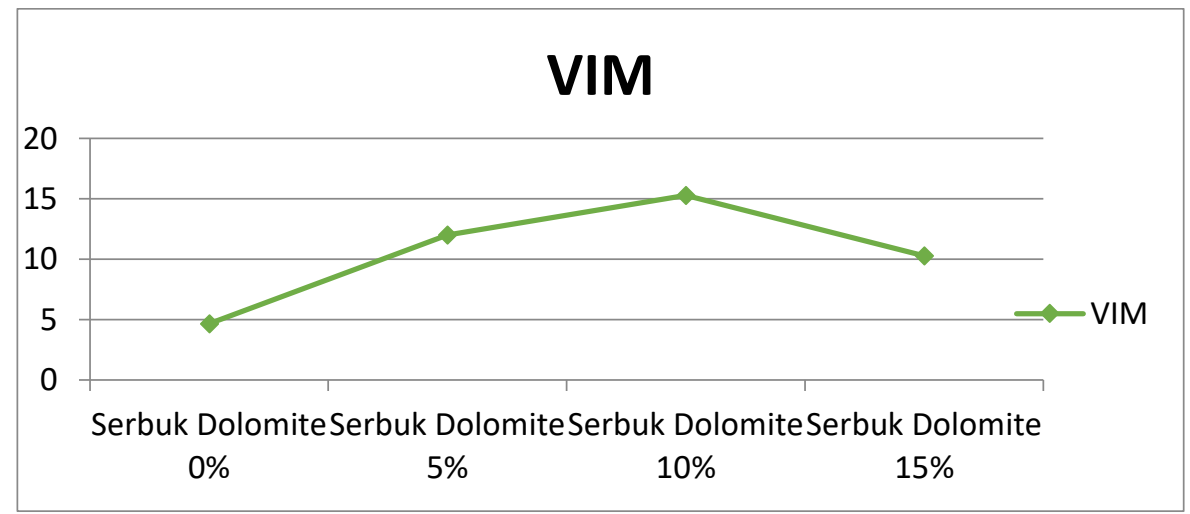

Sumber : lab. Teknik sipil universitas kadiri 
Grafik 2. Hubungan antara kadar serbuk dolomite terhadap nilai VMA

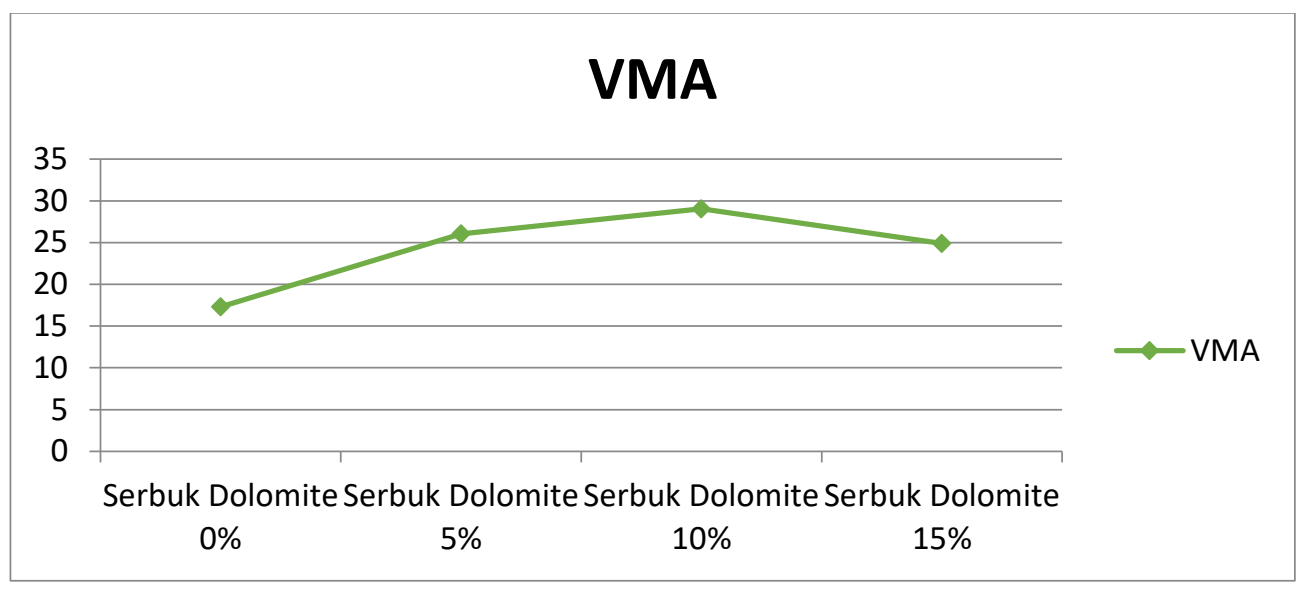

Sumber : lab. Teknik sipil universitas kadiri

Grafik 3. Memperlihatkan hubungan kandungan kadar padas dengan nilai VFB

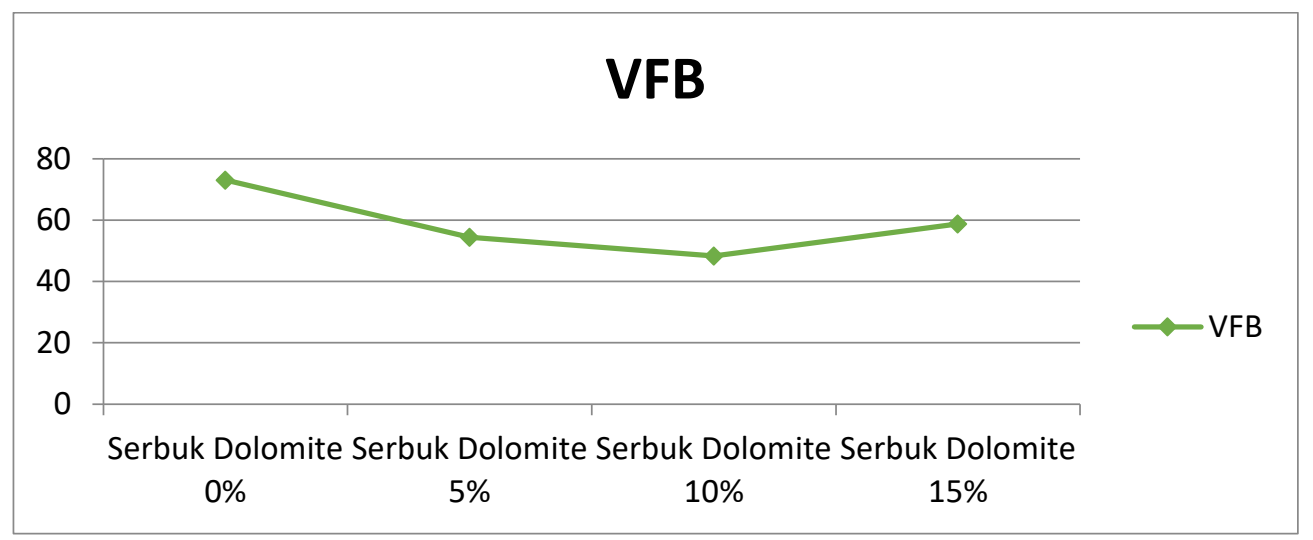

Sumber : lab. Teknik sipil universitas kadiri

Grafik 4. Hubungan antara kadar serbuk dolomite dengan nilai stabilitas

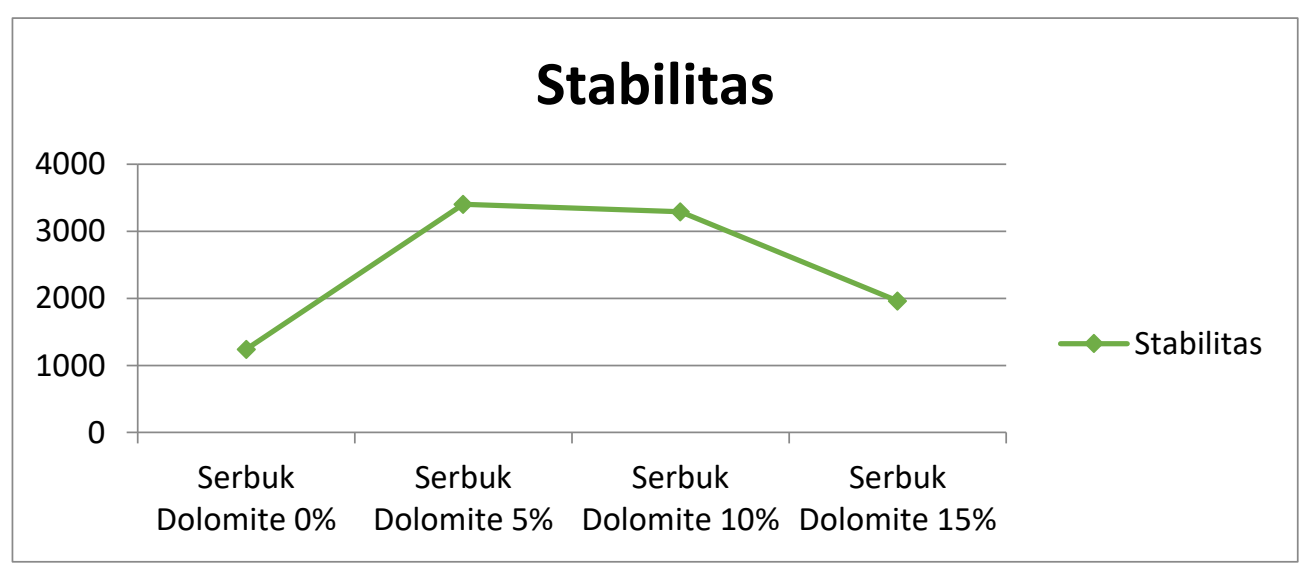

Sumber : lab. Teknik sipil universitas kadiri 
Grafik 5. Kadar optimum \& kadar Maximum

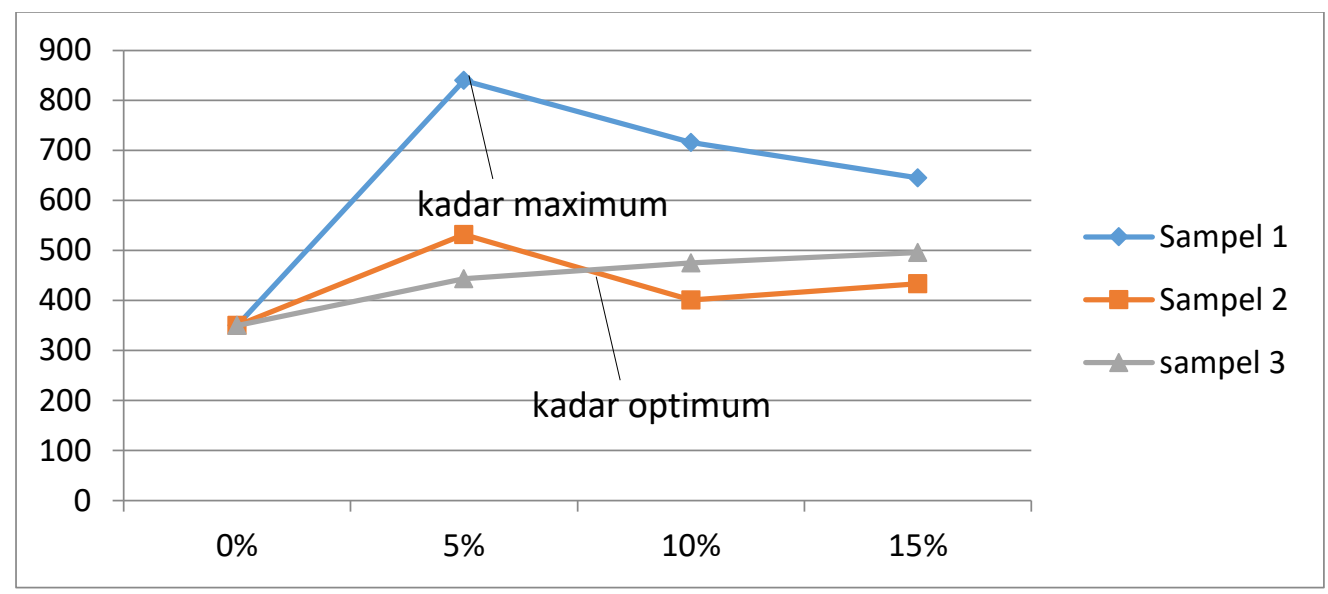

\section{Sumber : lab. Teknik sipil universitas kadiri}

Dari grafik 4.8 dapat disimpulkan bahwa kadar optimum campuran serbuk dolomite pada aspal beton pada kadar 5,5 sampai 8\% dan pada kadar maximum pada kadar 5\%.

\section{KESIMPULAN}

Penelitian ini dilakukan di laboratorium fakultas teknik universitas kadiri dengan hasil sebagai berikut :

1. Penambahan serbuk dolomite pada filler dan pasir brantas sebagai agregat halus pada campuran aspal beton dengan kadar 5\%, 10\% dan $15 \%$ menghasilkan volume rongga udara terhadap campuran (VIM) yaitu antara lain $11,991 \%, 15,281 \%$, dan $10.298 \%$.

2. Penambahan serbuk dolomite pada filler dan pasir brantas sebagai agregat halus pada campuran aspal beton dengan kadar 5\%, 10\% dan 15\% menghasilkan volume pori antara butir agregat (VMA) yaitu antara lain 26,302 \%, 29,057 \%, dan 24,884 \%.

3. Penambahan serbuk dolomite pada filler dan pasir brantas sebagai agregat halus pada campuran aspal beton dengan kadar 5\%, 10\% dan 15\% menghasilkan volume pori antara butir agregat yang terisi aspal (VFB) yaitu antara lain 54,493\%, 48,336 \%, dan 58,815\%.

4. Dari hasil pengujian, untuk penambahan serbuk dolomite pada filler dan pasir brantas sebagai agregat halus mengalami penurunan pada nilai stabilitas dan dll dari pada campuran aspal beton normal, masing-masing penurunannya dengan pemambahan serbuk dolomite yaitu antara lain 5\% sebesar 3402,503 kg, 10\% sebesar 3294,03 kg, 15\% sebesar 1958,946 kg.

5. Penambahan serbuk dolomite pada filler dan pasir brantas sebagai agregat halus pada campuran aspal beton dengan kadar 5\%, 10\% dan 15\% menghasilkan Marshall Quotient (MQ) yaitu antara lain $733 \mathrm{~kg} / \mathrm{mm}, 456 \mathrm{~kg} / \mathrm{mm}$, dan $471 \mathrm{~kg} / \mathrm{mm}$. 
6. Untuk mencapai kadar optimum maka campuran serbuk dolomite pada aspal beton berkisar antara $<10 \%$ dan pada kadar maximum diperoleh pada kadar 5\%.

7. Dari hasil data diatas dapat disimpulkan bahwa penambahan serbuk dolomite pada filler dan pasir brantas sebagai agregat halus pada campuran aspal beton tidak disarankan untuk aspal kelas 1 karena tidak sesuai dengan syarat syarat yang ditentukan.

\section{SARAN}

Penambahan serbuk dolomite berpengaruh terhadap nilai stabilitas. Pada saat mencampurkan adonan aspal beton, sebaiknya dicampurkan secepat mungkin agar aspal tidak cepat menggumpal. Penambahan serbuk dolomite sangat berpengaruh dengan kwalitas aspal yang akan digunakan. Penambahan serbuk dolomite sebaiknya digunakan pada lingkup pekerjaan aspal swadaya, baik pada perkerasan kaku maupun pelebaran bahu jalan. Makanya dari itu masih banyak hal yang perlu dilakukan penelitian lebih lanjut agar pada campuran aspal beton dengan tambahan serbuk dolomite dan pasir brantas sebagai agregat halus dapat digunakan pada ruang lingkup pekerjaan teknik sipil yang lebih luas.

\section{UCAPAN TERIMAKASIH}

Dalam penyusunan artikel ini, penulis ucapkan terimakasih kepada dosen pembimbing dan Universitas Kadiri. Penulis berharap agar artikel ini dapat bermanfaat bagi pembaca.

\section{DAFTAR PUSTAKA}

[1] M. Zaenuri, R. Romadhon, A. Gunarto, and A. Cahyono, "PENELITIAN PENGGUNAAN BATU GAMPING SEBAGAI AGREGAT KASAR DAN FILLER PADA ASPAL CAMPURAN AC-BC," UKaRsT, vol. 2, no. 1, pp. 24-35, 2018.

[2] A. D. Limantara, A. I. Candra, and S. W. Mudjanarko, "Manajemen Data Lalu Lintas Kendaraan Berbasis Sistem Internet Cerdas Ujicoba Implementasi Di Laboratorium Universitas Kadiri,” 2017.

[3] P. R. Nahak, Y. C. S. P, and S. Winarto, "STUDI PERENCANAAN TEBAL PERKERASAN KONSTRUKSI JALAN RAYA PADA RUAS JALAN UMASUKAER DI KABUPATEN MALAKA,” Jurmateks, vol. 2, no. 1, pp. 75-85, 2019.

[4] D. J. B. Marga, "Departemen Pekerjaan Umum," Man. Kapasitas Jalan Indones. (MKJI 1997), Jakarta, 1997.

[5] H. Saputra, "Pengertian Beton Aspal," 2014. .

[6] C. Yulianto, Y. Cahyo, A. Ridwan, and A. I. Candra, "PENELITIAN PENAMBAHAN 
BAHAN ADITIF KAPUR PADAM SEBAGAI BAHAN PENGISI FILLER PADA CAMPURAN ASPAL BETON,” Jurmateks, vol. 1, no. 2, pp. 204-215, 2018.

[7] B. A. Harsono, S. Winarto, and Y. C. S, "PERENCANAAN PENINGKATAN JALAN PADA RUAS JALAN PACITAN-NGADIROJO,”Jurmateks, vol. 1, no. 2, pp. 291-302, 2018.

[8] N. Fauziah, "ANALISIS PENGARUH SUBSTITUSI ASBUTON LGA (LAWELE GRANULAR ASPHALT) PADA ASPAL PENETRASI 60/70 TERHADAP CAMPURAN ASPAL PORUS,” REKATS, vol. 1, no. 1, pp. 381-387, 2017.

[9] M. Kasan, "Karakteristik Stabilitas dan Stabilitas Sisa Campuran Beton Aspal Daur Ulang," Mektek, vol. 11, no. 2, pp. 134-146, 2009.

[10] A. I. Candra, "STUDI KASUS STABILITAS STRUKTUR TANAH LEMPUNG PADA JALAN TOTOK KEROT KEDIRI MENGGUNAKAN LIMBAH KERTAS,” UKaRsT, 2018, doi: 10.30737/ukarst.v2i2.255.

[11] S. E. Raya, P. Priyo, and H. Dwi, "Variasi Temperatur Pencampuran Terhadap Parameter Marshall pada Campuran Lapis Aspal Beton,” Jrsdd, vol. 3, no. 3, pp. 455-468, 2015.

[12] A. Kurniawan, S. Winarto, and Y. C. S. P, "STUDI PERENCANAAN PENINGKATAN JALAN PADA RUAS JALAN JALUR LINTAS SELATAN GIRIWOYO - DUWET STA. 10+000 - STA. 15+000," Jurmateks, vol. 2, no. 1, pp. 39-50, 2019.

[13] S. E. M. P. Umum, "Kementerian Pekerjaan Umum," Direktorat Jenderal Bina Marga, "Spesifikasi Umum Perkerasan Aspal Revisi, vol. 3, 2010.

[14] B. Marga, "Perkerasan Aspal, Spesifikasi Umum Divisi VI Revisi 3.” Jakarta, 2010.

[15] H. Kusharto, "Terhadap Perilaku Campuran Beton Aspal," J. Tek. Sipil dan Perenc., vol. 9, no. 1, pp. 55-63, 2007.

[16] [Kementerian PUPR]. Kementerian Pekerjaan Umum dan Perumahan Rakyat direktorat jendral bina marga and D. J. B. Marga, "Manual Desain Perkerasan Jalan," Nomor 02/M/BM/2013, 2013.

[17] S. Sukirman, Perkerasan lentur jalan raya, vol. 2. 1999.

[18] S. Sukarman, Beton Aspal Campuran Panas. Yayasan Obor Indonesia, 2003.

[19] M. AASTHO, "M 20-70 (2002) dan Revisi SNI 03-1737-1989," Spesifikasi AASHTO dan SNI untuk berbagai nilai penetrasi aspal.

[20] D. P. Umum, "Metode pengujian campuran aspal dengan alat Marshall," SNI 06-24891991, 1991.

[21] A. S. Amal, “Aspal Terhadap Nilai Stabilitas Marshall,” GAMMA, vol. 9, no. 2, pp. 81$85,2019$. 